\title{
Application and Mechanism of Superhydrophilic Surfaces for the Enhancement of $\mathrm{CO}_{2}-\mathrm{H}_{2} \mathrm{O}$ Absorption
}

Yujia Chen, Ji Li, Pan Wu, Yunyi He, Jian He, Changjun Liu, Wei Jiang*

Low-Carbon Technology and Chemical Reaction Engineering Laboratory, School of Chemical Engineering, Sichuan University, Chengdu 610065, P.R. China

E-mail: weijiang@scu.edu.cn

The mixing ratio of superhydrophilic coatings, the amount of glue and the amount of $\mathrm{SiO}_{2}$ powder were discussed. The results obtained have now been added to the supporting information (Figure S1). We found that all samples within the test range can achieve superhydrophilic properties, comprehensive cost and other factors, combined with the stable superhydrophilic effect after modification, select the best one as the formula used in the manuscript.
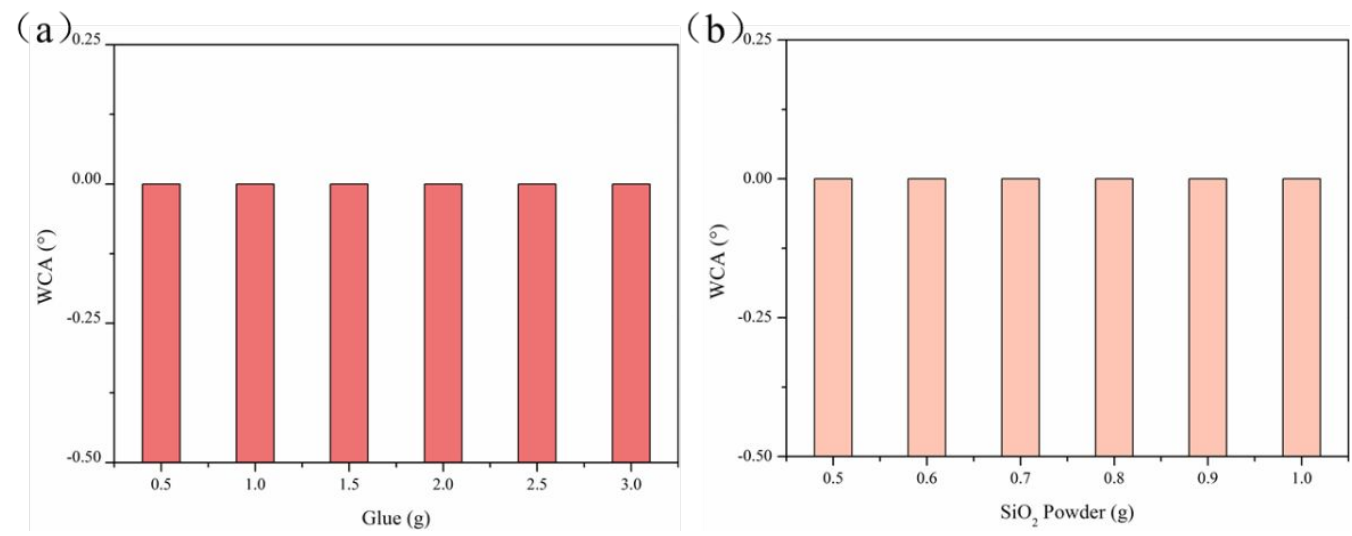

Fig. S1. Research on proportioning of superhydrophilic coatings: (a) amount of glue; (b) amount of $\mathrm{SiO}_{2}$ powder. 
Figure S2 shows the experimental device for falling film flow and absorption. The size of this device is $450 \times 10 \times 10 \mathrm{~mm}$. There is a water storage tank on the top of the device, and the liquid in the tank is spread on the experimental surface after passing through a slender slit with a width of $2 \mathrm{~mm}$. There is a direct $10 \mathrm{~mm}$ water removal port at the bottom of the device.

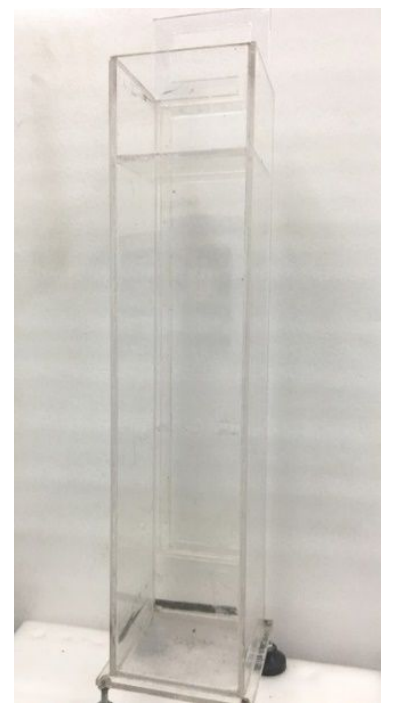

Fig. S2. Device for falling film flow and absorption operation. 
Through the scanning electron microscope (SEM) results (Figure S3), it can be seen that the surface of the unmodified stainless steel mesh is relatively smooth; the surface of the superhydrophobic modified stainless steel mesh has uneven block protrusions and vertical and horizontal ravines. After the superhydrophilic modification of the stainless steel mesh, it can be seen from the SEM image that many unevenly distributed spherical particles of different sizes are adhered to the surface of the stainless steel, forming a complex micro-nano structure.
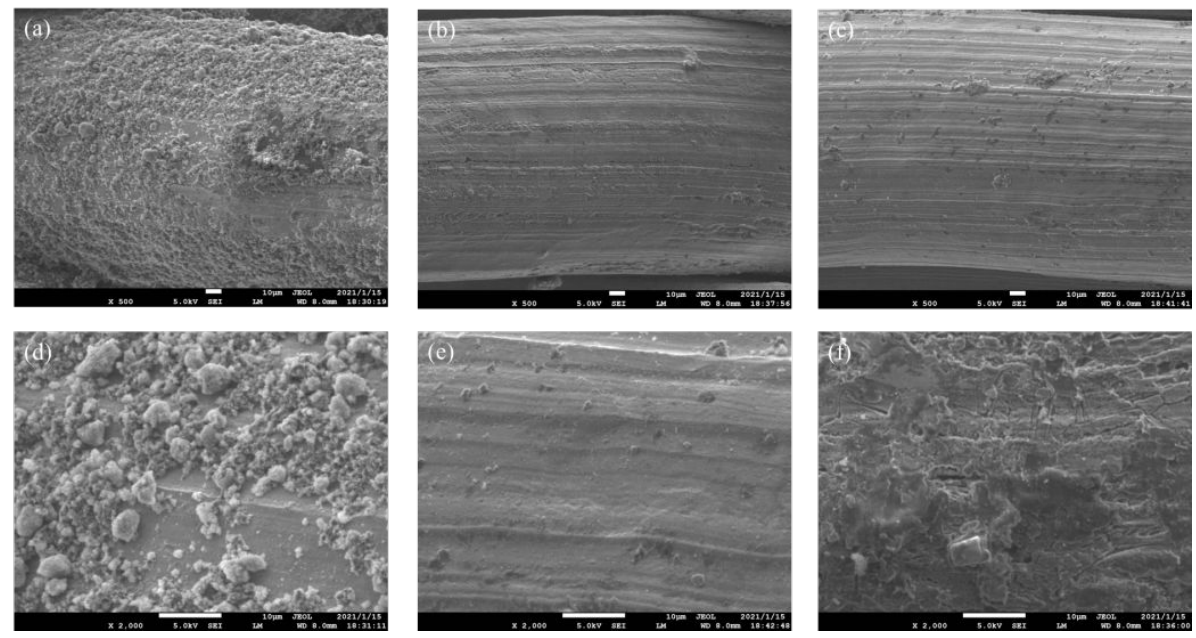

Fig. S3. Micromophology of three type of stainless steel mesh (SEM): (a) superhydrophilic stainless steel mesh $(\times 500)$, (b) normal stainless steel mesh $(\times 500)$, (c) superhydrophobic stainless steel mesh $(\times 500)$, (d) superhydrophilic stainless steel mesh $(\times 2000)$, (e) normal stainless steel mesh $(\times 2000)$, (f) superhydrophobic stainless steel mesh $(\times 2000)$. 
The distribution of elements in the stainless steel mesh after superhydrophilic modification was analyzed by energy dispersion spectroscopy (EDS mapping). As shown in Figure S4, a large amount of Si and O elements appeared on the surface of the superhydrophilic modified stainless steel mesh. And the weight percentage of Si element is about $10 \%$, and $\mathrm{O}$ element is twice that, indicating that it should be $\mathrm{SiO}_{2}$. The $\mathrm{C}$ element comes from commercial glue. This result confirms that $\mathrm{SiO}_{2}$ particles have been successfully introduced on the surface of the stainless steel mesh.

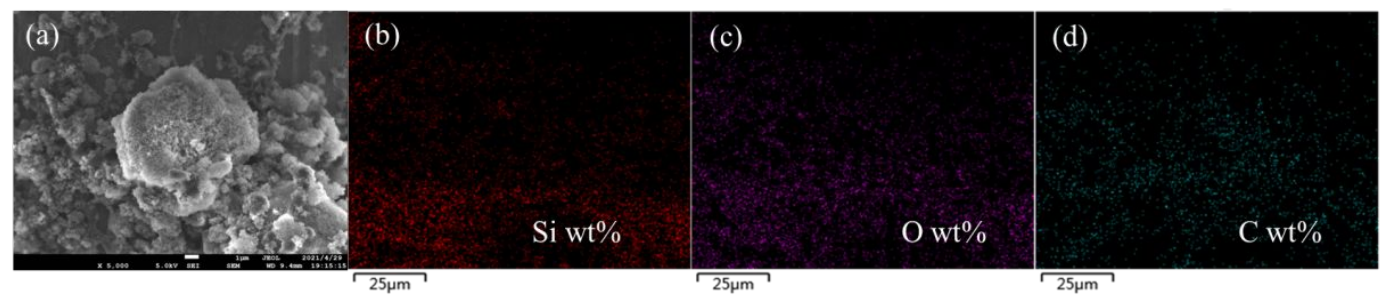

Fig. S4. SEM/EDS mapping image of stainless steel mesh after superhydrophilic modification. 
Compare the unmodified stainless steel mesh and the superhydrophilic modified stainless steel mesh infrared diffuse reflectance spectroscopy (FT-IR), as shown in Figure S5. The modified stainless steel mesh has obvious absorption peaks at 1080 $\mathrm{cm}^{-1}$ and $800 \mathrm{~cm}^{-1}$, which correspond to the stretching vibration of Si-O and the symmetrical stretching vibration of Si-O-Si, respectively. This result confirms that the $\mathrm{SiO}_{2}$ particles have been successfully loaded onto the surface of the stainless steel mesh.

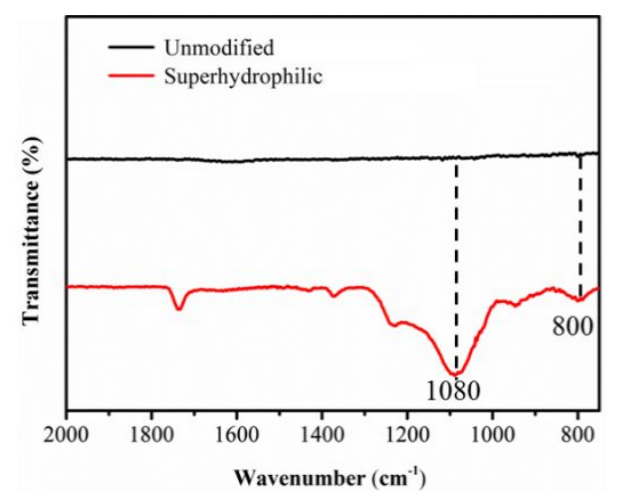

Fig. S5. FT-IR analysis of two kinds of stainless steel mesh. 
Figure S6 describes the continuous enlargement tendency of wetted area of all three samples by continuously dropping water onto the same point at the surface of horizontally placed samples, recording the diameter of round wetted watermark and calculating the wetted area against water amount. Although the enlarging rate of superhydrophilic surface is significantly faster than $90^{\circ}$-WCA sample. The wetted area of superhydrophobic surface almost can be ignored although the moistened surface area still expanded.

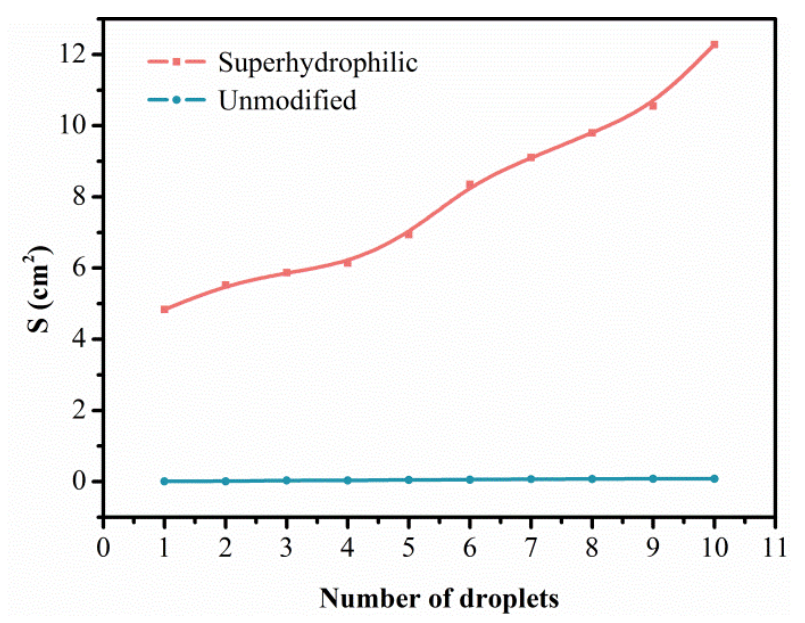

Fig. S6. The continuous enlargement tendency of wetted area of superhydrophilic and unmodified surface. 
Figure S7 describes the flow state of liquid on the surface with a liquid contact angle of $20^{\circ}$ without reverse gas velocity at different liquid inlet velocities. Similarly, the flow direction of the liquid in the inlet section is inclined downward until it touches the boundary and retracts. Comparing with different liquid inlet velocity, it is found that the wetted area ratio of the surface with WCA equals to $20^{\circ}$ increases from $90.9 \%$ of liquid inlet velocity of $0.5 \mathrm{~m} / \mathrm{s}$ to $94.8 \%$ when the liquid inlet velocity is 1 $\mathrm{m} / \mathrm{s}$. Although the liquid flow state on the surface with water contact angle of $20^{\circ}$ is very close to that on the superhydrophilic surface, the difference between the two can be reflected by the proportion of the total wetted area.

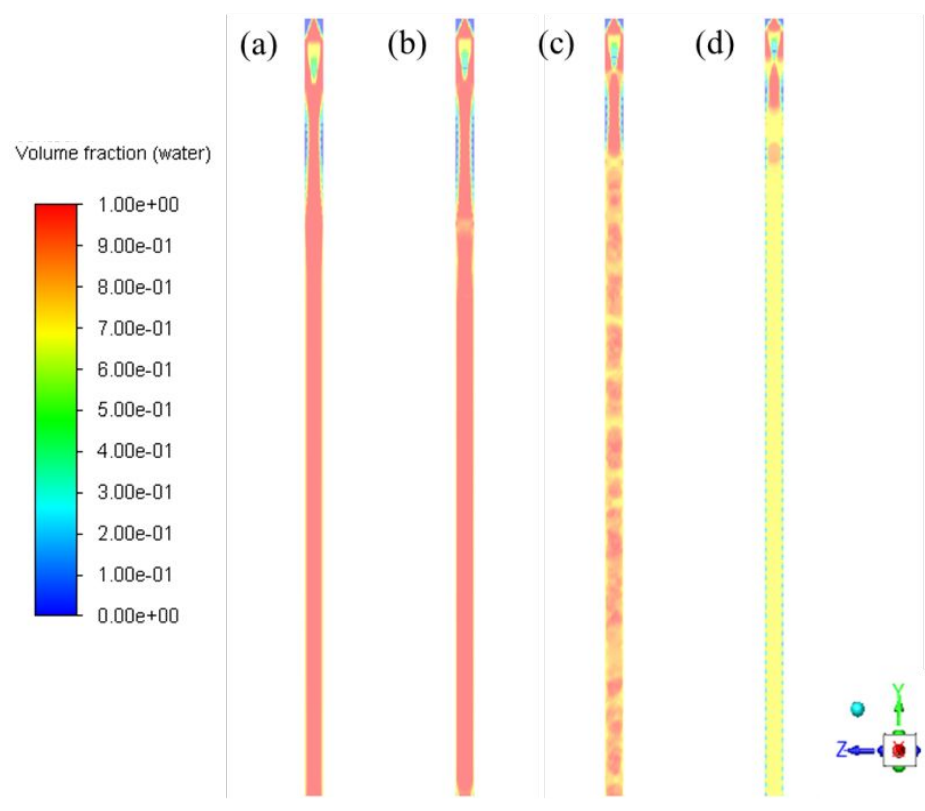

Fig. S7. Simulation results of liquid diffusion on the surface with water contact angle equals to $20^{\circ}:$ (a) Inlet liquid velocity $=1 \mathrm{~m} / \mathrm{s}$; (b) Inlet liquid velocity $=0.85 \mathrm{~m} / \mathrm{s}$; (c) Inlet liquid velocity $=0.65 \mathrm{~m} / \mathrm{s}$; ( d) Inlet liquid velocity $=0.5 \mathrm{~m} / \mathrm{s}$. 
Figure S8 describes the flow state of liquid on the surface with liquid contact angle of $60^{\circ}$ without reverse gas velocity at different liquid inlet velocity. At this time, the flow direction of the liquid in the entrance section is also inclined downward, but it has retracted without touching the boundary. When the flow distance is less than $0.1 \mathrm{~m}$, the flow shape is similar to gourd, and the flow boundary is almost parallel to the long side of the surface. In addition, when the liquid velocity is $0.5 \mathrm{~m} / \mathrm{s}$, the specific wetted area ratio of the surface is greatly reduced to $30.7 \%$. Even if the liquid velocity is increased to $1 \mathrm{~m} / \mathrm{s}$, the wetted area ratio is only increased to $32.1 \%$.

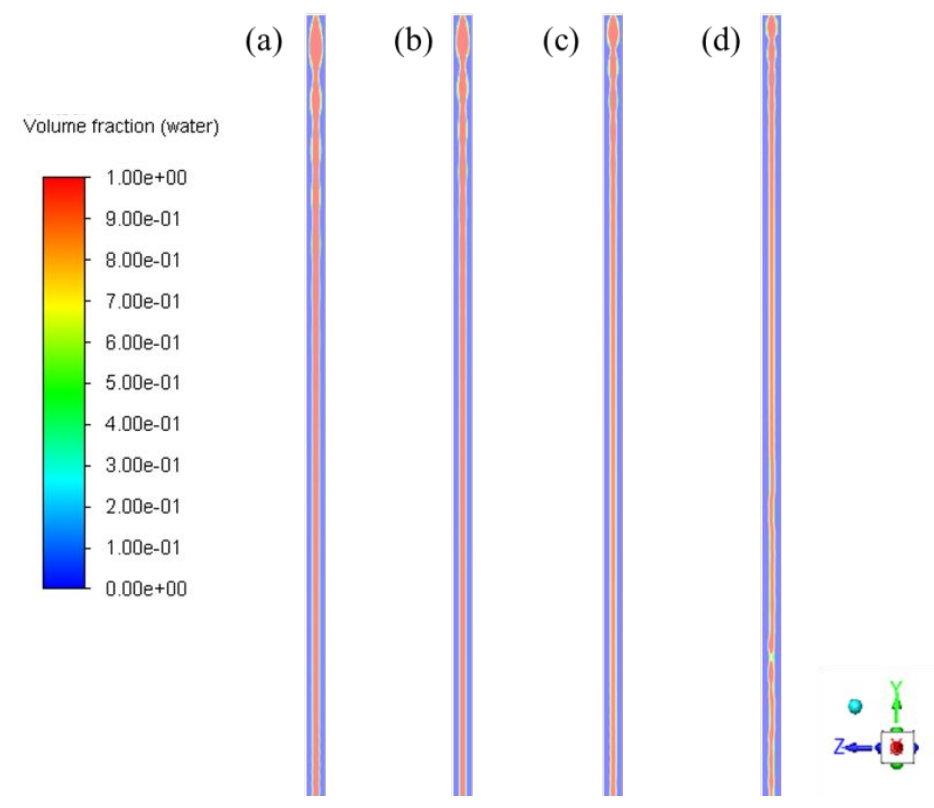

Fig. S8. Simulation results of liquid diffusion on the surface with water contact angle equals to $60^{\circ}:$ (a) Inlet liquid velocity $=1 \mathrm{~m} / \mathrm{s}$; (b) Inlet liquid velocity $=0.85 \mathrm{~m} / \mathrm{s}$; (c) Inlet liquid velocity $=0.65 \mathrm{~m} / \mathrm{s}$; (d) Inlet liquid velocity $=0.5 \mathrm{~m} / \mathrm{s}$. 
Figure S9 describes the flow state of liquid on the surface with a liquid contact angle of $120^{\circ}$ without reverse gas velocity at different liquid inlet velocities. At this time, the flow direction of the liquid in the inlet section is almost vertical and parallel to the long edge of the surface. With the increase of water contact angle to $120^{\circ}$, it is found that the liquid cannot be continuous on the surface when the liquid inlet velocity is $0.65 \mathrm{~m} / \mathrm{s}$. When the liquid inlet is further reduced to $0.5 \mathrm{~m} / \mathrm{s}$, it is found that the position of liquid cutoff is closer to the water inlet.

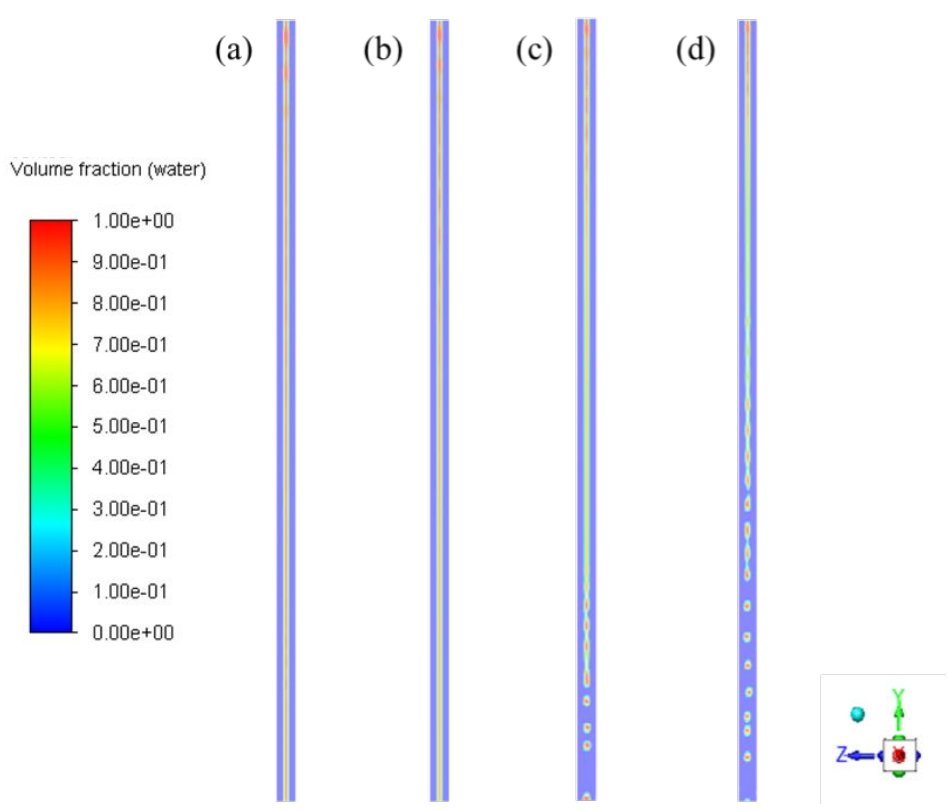

Fig. S9. Simulation results of liquid diffusion on the surface with water contact angle equals to $120^{\circ}$ : (a) Inlet liquid velocity $=1 \mathrm{~m} / \mathrm{s}$; (b) Inlet liquid velocity $=0.85 \mathrm{~m} / \mathrm{s}$; (c) Inlet liquid velocity $=0.65 \mathrm{~m} / \mathrm{s}$; (d) Inlet liquid velocity $=0.5 \mathrm{~m} / \mathrm{s}$. 
Figure S10 describes the influence of different reverse gas velocity on the flow of liquid on superhydrophilic surface. It can be found through S9 that when the reverse gas velocity is less than the flooding gas velocity, the influence of reverse gas velocity on the flow velocity of liquid film is not significant.
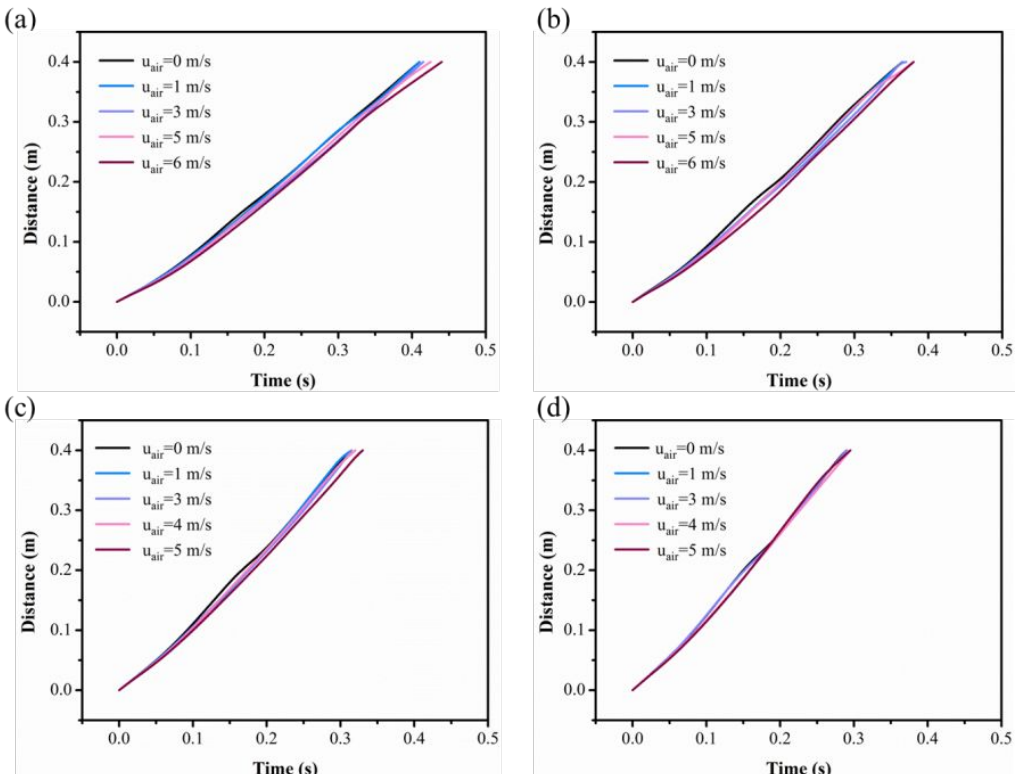

Fig. S10. The influence of reverse gas velocity on the flow of liquid on superhydrophilic surface. (a) the liquid inlet velocity is $0.5 \mathrm{~m} / \mathrm{s}$; (b) the liquid inlet velocity is $0.65 \mathrm{~m} / \mathrm{s}$; (c) the liquid inlet velocity is $0.85 \mathrm{~m} / \mathrm{s}$; (d) the liquid inlet velocity is $1 \mathrm{~m} / \mathrm{s}$. 
Figure S11 describes the influence of different reverse gas velocity on the liquid flow on the surface with water contact angle of $20^{\circ}$. It can be found that when the reverse gas velocity is less than the flooding gas velocity, the influence of reverse gas velocity on the liquid film flow velocity is also small.
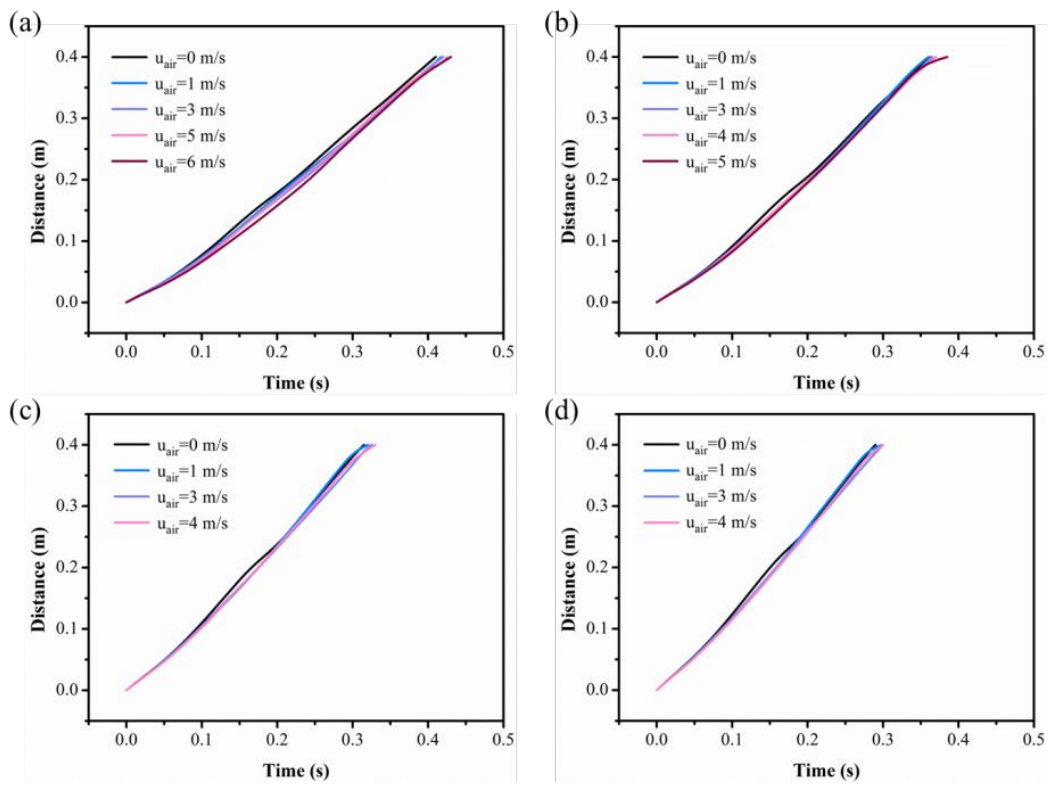

Fig. S11. The influence of reverse gas velocity on the flow of liquid on the surface with WCA equals to $20^{\circ}$. (a) the liquid inlet velocity is $0.5 \mathrm{~m} / \mathrm{s}$; (b) the liquid inlet velocity is $0.65 \mathrm{~m} / \mathrm{s}$; (c) the liquid inlet velocity is $0.85 \mathrm{~m} / \mathrm{s}$; (d) the liquid inlet velocity is $1 \mathrm{~m} / \mathrm{s}$. 
Figure S12 describes the influence of different reverse gas velocity on the liquid flow on the surface with water contact angle of $90^{\circ}$. Through S11, it can be found that when the reverse gas velocity is less than the flooding gas velocity, the reverse gas velocity has little influence on the liquid film flow velocity.

(a)

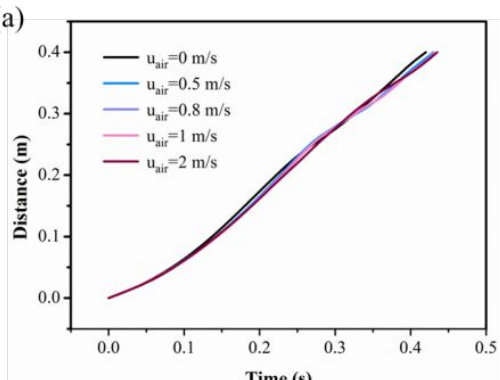

(c)

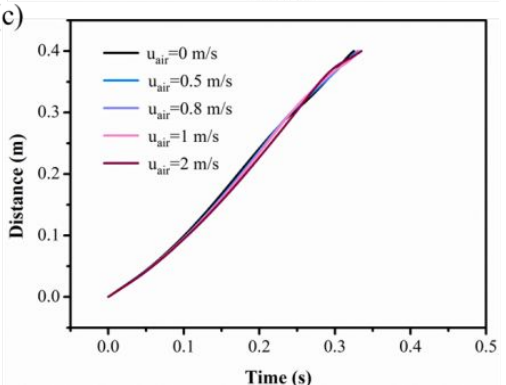

(b)

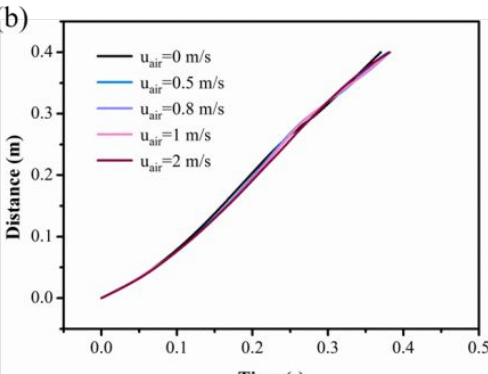

(d)

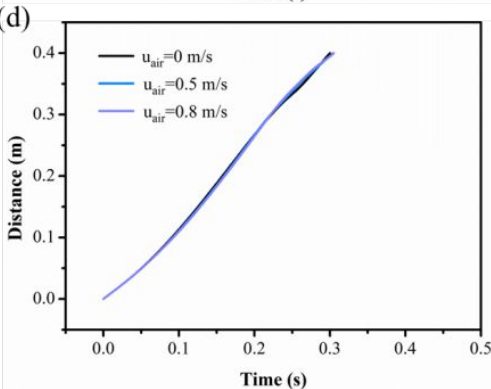

Fig. S12. The influence of reverse gas velocity on the flow of liquid on the surface with WCA equals to $90^{\circ}$. (a) the liquid inlet velocity is $0.5 \mathrm{~m} / \mathrm{s}$; (b) the liquid inlet velocity is $0.65 \mathrm{~m} / \mathrm{s}$; (c) the liquid inlet velocity is $0.85 \mathrm{~m} / \mathrm{s}$; (d) the liquid inlet velocity is $1 \mathrm{~m} / \mathrm{s}$. 
As shown in the recorded video and Figure S13a, the water wetting on packing surface has been detected when water volume flow rate is $29.299 \mathrm{~m}^{3} /\left(\mathrm{m}^{2} \bullet \mathrm{h}\right)$,. Further increasing the water volume flow rate to $52.229 \mathrm{~m}^{3} /\left(\mathrm{m}^{2} \bullet \mathrm{h}\right)$, the complete wetting and observable flowing stream can be visibly observed. Almost all packing surface is covered by water without detectable channeling and refracted flow, and no dry plate remains. Comparably, for unmodified structured packing tower, as shown in the video and Figure S13b, the wetting of outermost corrugated sheet is difficult to be observed when water flow rate is small, but gradually appears with the increasing of flow rate until to be completely wetted when water volume flow rate reaching 58.599 $\mathrm{m}^{3} /\left(\mathrm{m}^{2} \bullet \mathrm{h}\right)$. However, some visible channeling flow on packing surface can be observed, especially at the connection turning point of corrugation between two packing layers. This suggests the wetting status of unmodified structured packing is relatively worse than superhydrophilic one.

When superhydrophobic structured packing is used, the occurrence is totally different. The packing surface is hardly to be wetted, and keeps dry status basically. The fed water forms droplets spontaneously, and rolls off the packing quickly (Fig. $\mathrm{S} 13 \mathrm{c})$. This continuous droplet flow ascribes to the strong water-repellency of packing surface. In all testing range, no observable flooding occurrence is found and only the mist concentration in tower turns thicker. Water droplets are always taken out by upwards gas. Thereby, the flooding of superhydrophobic tower is out of consideration.
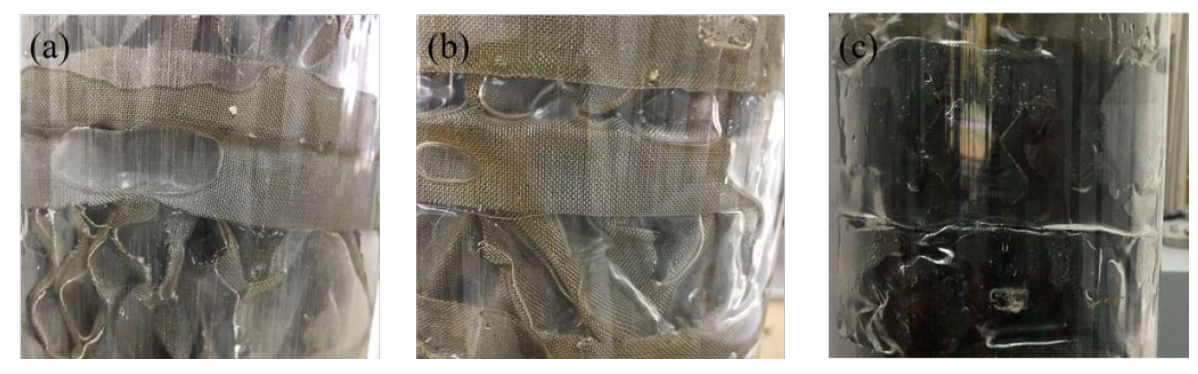

Fig. S15. Wetting condition and flow phenomenon of three kinds of structured packing in the tower: (a) Wetting condition of superhydrophilic structured packing when the liquid flow rate is $29.299 \mathrm{~m}^{3} /\left(\mathrm{m}^{2} \bullet \mathrm{h}\right)$; (b) Wetting condition of unmodified structured packing when the liquid flow rate is $58.599 \mathrm{~m}^{3} /\left(\mathrm{m}^{2} \bullet \mathrm{h}\right)$; (c) The flow phenomenon of liquid on the surface of superhydrophobic structured packing. 
Figure S14 shows the relationship between pressure drop and F-factor of three kinds of structured packing beds under the same water volume flow rate. It can be confirmed by S10 that the pressure drop of superhydrophilic structured packing bed is very similar to that of unmodified packing bed when the packing is just wetted. When there is absorbent, the order of pressure drop of three structured packing beds is that superhydrophilic packing bed is slightly larger than unmodified packing bed and far larger than superhydrophobic packing bed.

(a)

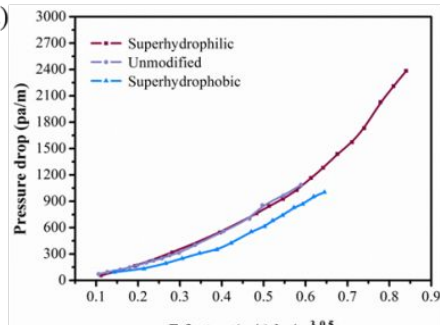

(c)

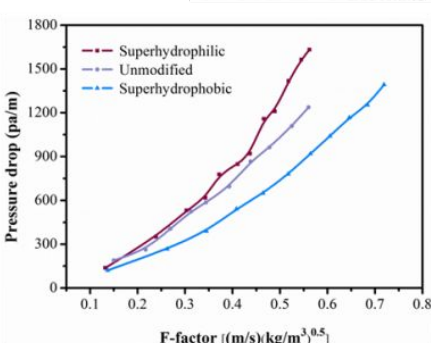

(d)

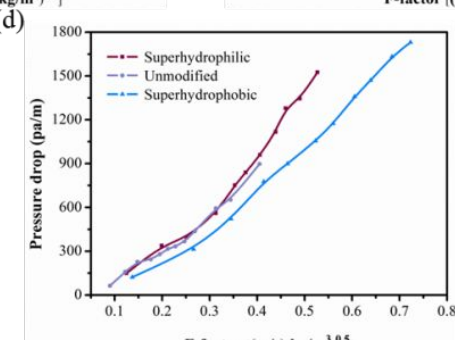

(b)

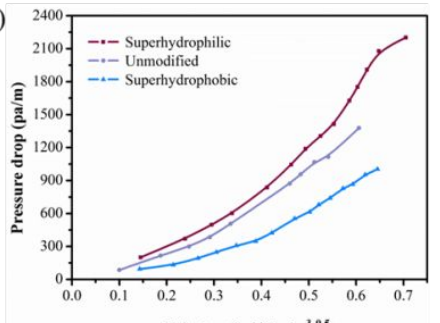

(e)

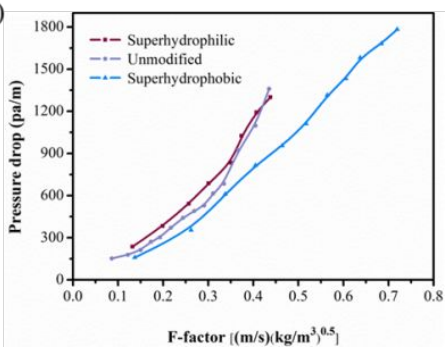

Fig. S14. The relationship between the pressure drop and the F-factor for the three tested types of structured packings at same liquid loadings. (a) wet packings; (b) $\mathrm{L}=0.55 \mathrm{~m}^{3} / \mathrm{h}$; (c) $\mathrm{L}=0.65 \mathrm{~m}^{3} / \mathrm{h}$; (d) $\mathrm{L}=1.13 \mathrm{~m}^{3} / \mathrm{h}$; (e) $\mathrm{L}=1.37$ $\mathrm{m}^{3} / \mathrm{h}$. 
Figure S15 shows the relationship between liquid holding capacity and F-factor of three kinds of structured packing bed under the same water volume flow rate. It can be found that under the same volume flow rate of water, the liquid holding capacity of the three kinds of packing beds is flowing the order that the unmodified packing bed is larger than that of the superhydrophilic packing bed than that of the superhydrophobic packing bed. Among them, the liquid holding capacity of all superhydrophobic packing beds presents a downward trend after the loading point.

(a)

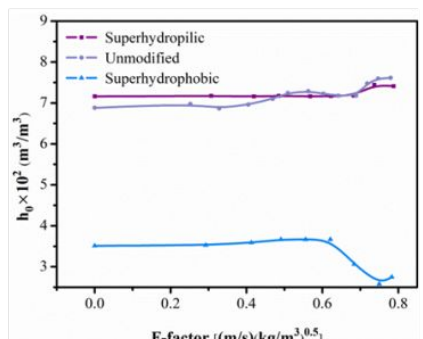

(c)

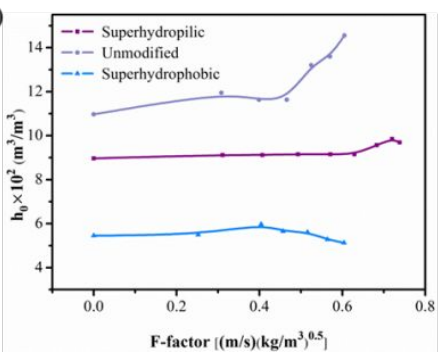

(b)

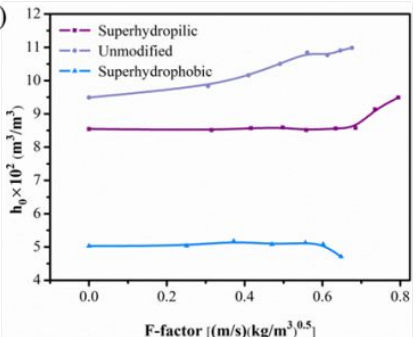

(d)

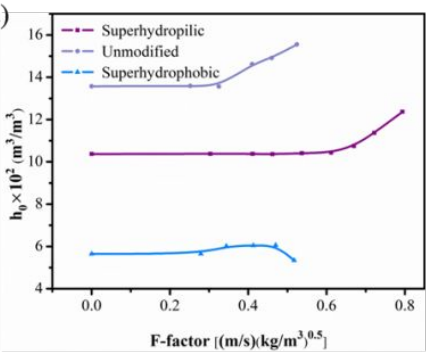

(e)

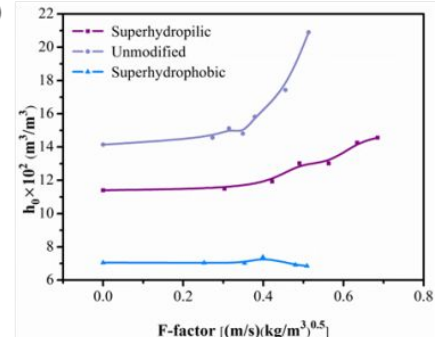

Fig. S15. The relationship between the F-factor and the liquid holding capacity for the three tested types of structured packings at same liquid loadings. (a) $\mathrm{L}=0.19 \mathrm{~m} / \mathrm{s} ;$ (b) $\mathrm{L}=0.27 \mathrm{~m} / \mathrm{s} ;$ (c) $\mathrm{L}=0.41 \mathrm{~m} / \mathrm{s} ;$ (d) $\mathrm{L}=0.53 \mathrm{~m} / \mathrm{s}$; (e) 
The flooding gas velocity of structured packing bed shown in Figure S16 exhibits that $u_{f}$ of superhydrophilic structured packing is always greater than that of unmodified structured packing, but of superhydrophobic structured packing is unobservable since flooding occurs at very low gas velocity. The determined $u_{f}$ of superhydrophilic tower is about $20 \%$ higher than of unmodified tower at low liquid flow, but gradually rises to more than $50 \%$ higher. Similarly, the increase in the flooding speed of the superhydrophilic structured packing is also attributed to the superhydrophilic surface characteristics, which promotes the liquid to "suck" tightly on the superhydrophilic surface and is not easy to be picked up.

The results are agreed with simulation, and confirm the wider operation range of superhydrophilic one than the unmodified.

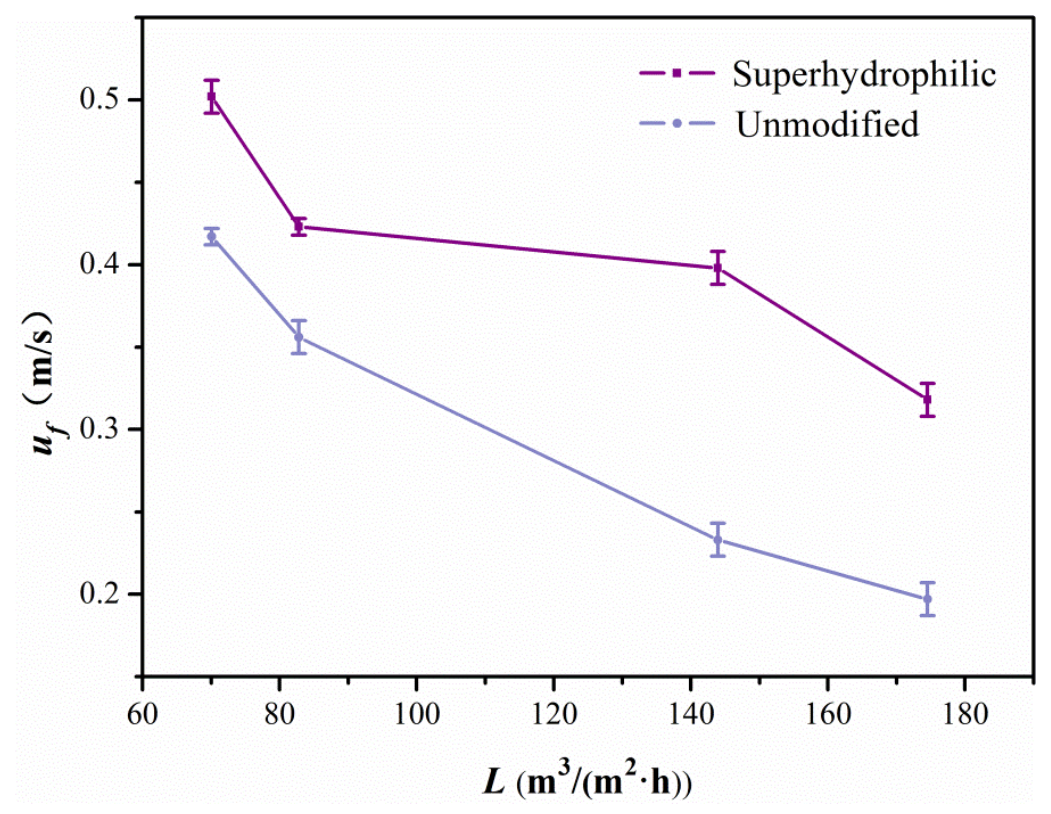

Fig. S16. The experimental $\mathrm{u}_{\mathrm{f}}$ values for the structured packing. 
Figure S17 show the results of the mass transfer coefficient of three kinds of structured packing at different liquid volume flow. It can be seen that the superhydrophilic modification of the packing is effective for enhancing absorption and mass transfer coefficient, and the mass transfer coefficient of superhydrophilic pcaking exceeds the unmodified ones $10 \%$ at least. The superhydrophobic ones is close to the unmodified ones, this is because the micro-nano structure of the superhydrophobic surface is very vulnerable, so under the the continuous impact of flowing water, the packing partially lost superhydrophobic properties.

(a)

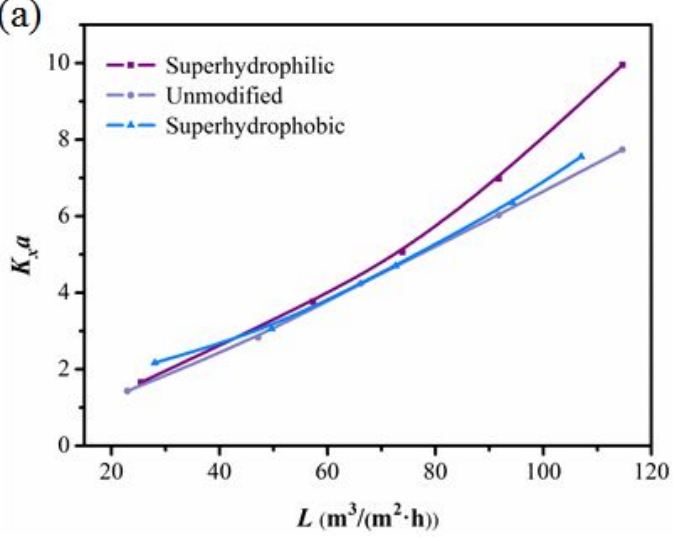

(b)

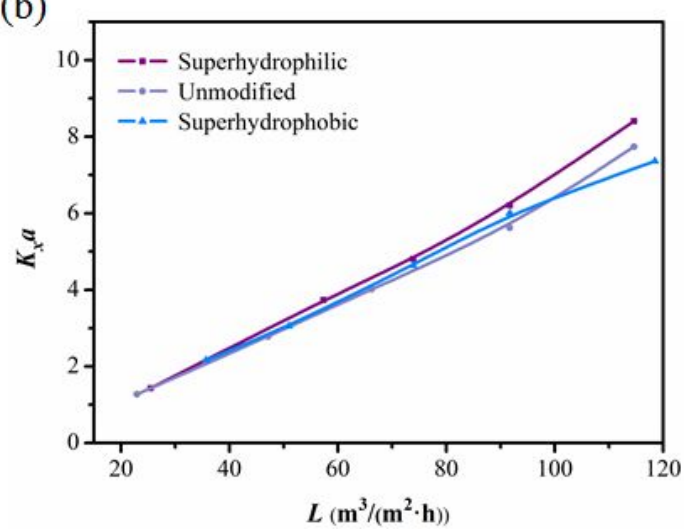

Fig. S17. Mass transfer coefficient of three kinds of structured packing under different liquid volume flow: (a) $\mathrm{G}=1200 \mathrm{~L} / \mathrm{h} ;(\mathrm{b}) \mathrm{G}=1500 \mathrm{~L} / \mathrm{h}$. 
